Article

\title{
Negative Impact of Wound Complications on Oncologic Outcome of Soft Tissue Sarcomas of the Chest Wall
}

\author{
Mehran Dadras *, ${ }^{+}$, Pascal Koepp ${ }^{\dagger}$, Johannes Maximilian Wagner, Christoph Wallner, \\ Maxi Sacher, Marcus Lehnhardt, Björn Behr $\ddagger$ and Kamran Harati $\ddagger$ \\ Department of Plastic Surgery, BG University Hospital Bergmannsheil, 44787 Bochum, Germany \\ * Correspondence: mehran.dadras@rub.de \\ + These authors share the first authorship. \\ $\ddagger$ These authors share the last authorship.
}

Received: 9 December 2019; Accepted: 29 December 2019; Published: 31 December 2019

\begin{abstract}
A link of complications with worse oncologic prognosis has been established for multiple malignancies, while the limited literature on soft-tissue sarcomas is inconclusive. The aim of this study was to examine risk factors and the oncologic impact of wound complications after curative resection of primary soft-tissue sarcomas of the chest wall. Patients with primary soft tissue sarcomas of the chest wall were identified. Groups with and without wound complications were compared by using univariate and multivariate analysis to identify risk factors. For patients with clear surgical margins (R0), univariate and multivariate analysis of factors associated with 5-year local recurrence free survival (LRFS), metastasis free survival (MFS), and disease specific survival (DSS) were performed. A total of 102 patients were included in the study. Wound complications occurred in 11 patients $(10.8 \%)$ within 90 days. Cardiovascular morbidity and operation time represented independent risk factors for wound complications. In 94 patients with clear surgical margins, those with wound complications had an estimated 5-year LRFS of 30\% versus $72.6 \%$ and a 5 -year DSS of 58.3\% versus $82.1 \%$. Wound complications could be identified as an independent predictor for worse LRFS and DSS. Patients with a high risk of wound complications should be identified and strategies implemented to reduce surgical complications and possibly improve oncologic prognosis.
\end{abstract}

Keywords: soft tissue sarcoma; wound complications; tumor; chest wall

\section{Introduction}

Soft tissue sarcomas (STS) represent a heterogeneous group of malignant tumors with mesenchymal origin and represent around 1\% of all adult malignancies [1]. Of these, approximately 10\% arise from the chest wall [1,2].

Surgical resection is considered to be the cornerstone of treatment, while complete resection offers the potential for curative treatment.

Among the factors that are predictive for oncologic outcome, surgical margins, histological grade and subtype, tumor size, and depth are considered to be the most significant [2-6].

Multiple studies have addressed the impact of multimodal therapy on the treatment of STS. While radiotherapy has been shown to improve local control, the timing of therapy as adjuvant or neoadjuvant has been a subject for debate. It could be observed that neoadjuvant radiotherapy increases the risk of wound complications, whereas more fibrosis has been observed in adjuvant application [7-9]. According to German guidelines, radiotherapy of soft tissue sarcomas is recommended in high-grade lesions and tumors $>5 \mathrm{~cm}$ in maximum diameter $[10,11]$, but use of multimodal therapy ultimately remains a case-by-case decision based on individual factors. 
Local inflammatory complications have been identified as a predictor for cancer recurrence and long-term oncologic outcome in various malignancies. An association of anastomotic leak with higher local recurrence rates has been shown for colorectal, esophagus, and gastric cancer [12-14]. Similarly, wound complications have been shown to be a negative predictor for oncologic outcome of squamous cell carcinoma of the head and neck $[15,16]$ or breast cancer $[17,18]$.

So far, only two studies have addressed the impact of surgical complications on oncologic outcome of STS to our knowledge $[19,20]$. Both studies included patients with STS in different locations, incomplete resections, and significant differences in the application of multimodal therapy of the compared subgroups, representing possible biases for the results.

Thus, the aim of this study was to assess the oncological impact of surgical complications in a tightly defined patient population such as curative resections of primary STS of the chest wall.

Secondarily, predictors of surgical complications in this cohort of patients should be identified.

\section{Results}

A total of 144 patients with STS of the chest wall were treated at our institution between January 1995 and December 2016. After excluding 38 patients who initially presented with a sarcoma recurrence, two patients with metastatic disease upon diagnosis, and two patients with missing relevant data, the remaining 102 patients were included in the study. Sexes were equally distributed with 51 patients each. Median age upon resection of the tumor was 58 years. 56 patients presented at our institution primarily, while 46 patients had undergone prior external biopsy or insufficient operative treatment. The most prevalent histologic subtypes were undifferentiated pleomorphic sarcoma in 24 cases, liposarcoma in 17 cases, and angiosarcoma in 10 cases. The most common tumor locations were anterolateral thorax in 32 cases and lateral thorax in 28 cases, while 71 tumors were located below the deep fascia. In terms of size, 69 tumors were larger than $5 \mathrm{~cm}$ and the mean largest diameter was $9 \pm 9 \mathrm{~cm}$. Furthermore, 34 tumors were graded as G1, 29 as G2, and 39 as G3.

Full thickness resection of the thoracic wall was needed in 39 patients.

Soft tissue closure could be achieved primarily in 70 patients, seven patients received skin grafting, 24 patients received local grafting, and one patient received free microvascular flap coverage.

Negative margins could be achieved in 94 of patients, while microscopical (R1) incomplete resection was performed in four cases and macroscopical incomplete resection (R2) was performed in four cases.

Five patients received neoadjuvant therapy, as all of these patients had a high grade (G2/G3) tumor. Out of these patients, one received neoadjuvant radiotherapy, two received chemotherapy, and two received combined radiochemotherapy.

Adjuvant radiotherapy was administered to 33 patients with a mean dose of $56 \pm 6$ Gray. Out of these patients, 31 had a high grade (G2/G3) tumor.

During the 90-days postoperative period, 45 patients developed complications as presented in Table 1. A total of 20 of these complications were classified as Clavien-Dindo (CD) grade 1 and hence as being very minor. Meanwhile, 25 patients developed a CD grade $\geq 2$ complication. Wound infections occurred in 13 patients, nine of which underwent operative treatment. Only CD grade $\geq 2$ overall and wound complications were considered for further analysis. 
Table 1. Postoperative complications by Clavien-Dindo grade.

\begin{tabular}{ccccccc}
\hline \multirow{2}{*}{ Complication } & \multicolumn{7}{c}{ Clavien-Dindo Grade [21] } \\
\cline { 2 - 7 } & I & II & IIIa & IIIb & IV & Total \\
\hline Respiratory tract infection & - & 1 & - & - & 1 & 2 \\
Urinary tract infection & - & 2 & - & - & - & 2 \\
Hemorrhage/Anemia & 8 & 5 & - & 2 & 2 & 17 \\
Wound complication & 2 & 2 & - & 9 & - & 13 \\
Seroma formation & 11 & - & - & 3 & - & 14 \\
Pneumothorax & - & - & 4 & - & - & 4 \\
All Patients (highest grade complication) & 20 & 7 & 4 & 11 & 3 & 45 \\
\hline
\end{tabular}

Clavien Dindo classification: Grade I: Any deviation from the normal postoperative course without the need for pharmacological treatment except for a number of allowed substance categories or surgical, endoscopic, and radiological interventions. Grade II: Requiring pharmacological treatment with drugs other than the ones allowed for grade I. Grade III: Requiring surgical, endoscopic or radiological intervention (a: under local anesthesia; b: under general anesthesia). Grade IV: A life-threatening complication requiring intensive care treatment (a: single organ; b: multi- organ dysfunction). Grade V: death.

\subsection{Predictors of Wound Complications}

A comparison of groups with and without complications is presented in Table 2. A significantly higher proportion of obese patients developed wound complications, however obesity was eliminated in multivariate analysis. Both the ASA-score and cardiovascular morbidity were significantly higher in the wound complication group, in multivariate analysis the ASA-score was eliminated by cardiovascular morbidity, which represented an independent predictor of wound complications with an odds ratio of $5.07(1.11-23.16)$ and $p=0.036$.

Neither tumor depth, location, nor size showed significant differences in the patient group with and without wound complications, yet the wound complication rate of tumors $<5 \mathrm{~cm}$ was $6 \%$ compared to $23 \%$ in tumors $>15 \mathrm{~cm}$. Angiosarcomas had the highest wound complication rate with $30 \%$, while the distribution of histologic types of sarcoma did not differ significantly overall. No association of wound complications was identified with the stage of disease, tumor grade, or resection status but operation time represented an independent predictor of wound complications with an odds ratio of 1.01 (1.001-1.02) per minute, $p=0.025$. Patients with complex soft tissue coverage did not have a higher wound complication rate. 
Table 2. Population and comparison of groups with and without wound complications.

\begin{tabular}{|c|c|c|c|c|c|c|}
\hline Variable & $\begin{array}{l}\text { All Patients } \\
(\mathrm{n}=102)\end{array}$ & $\begin{array}{l}\text { No Wound Complications } \\
(\mathrm{n}=91)\end{array}$ & $\begin{array}{l}\text { Wound Complications } \\
\qquad(\mathrm{n}=11)\end{array}$ & $\begin{array}{c}\text { Comparison, } \\
p \text {-value }\end{array}$ & $\begin{array}{l}\text { Logistic Multivariate } \\
\text { Regression, } p \text {-value }\end{array}$ & $\begin{array}{l}\text { Odds Ratio } \\
(95 \% \mathrm{CI})\end{array}$ \\
\hline Male & $51(50)$ & $43(47.3)$ & $8(72.7)$ & & & \\
\hline Female & $51(50)$ & $48(52.7)$ & $3(27.3)$ & & & \\
\hline Obesity $\left(\right.$ BMI $\left.>30 \mathrm{~kg} / \mathrm{m}^{2}\right)$ & & & & 0.033 & * & \\
\hline Yes & $21(20.6)$ & $16(17.6)$ & $5(45.4)$ & & & \\
\hline No & $81(79.4)$ & $75(82.4)$ & $6(54.5)$ & & & \\
\hline ASA-Classification & & & & 0.005 & * & \\
\hline 3 & $22(21.6)$ & $15(16.5)$ & $7(63.6)$ & & & \\
\hline 4 & $2(2)$ & $2(2.2)$ & 0 & & & \\
\hline Cardiovascular Morbidity & & & & 0.026 & 0.036 & $5.07(1.11-23.16)$ \\
\hline Yes & $41(40.2)$ & $33(36.3)$ & $8(72.7)$ & & & \\
\hline No & $61(59.8)$ & $58(63.7)$ & $3(27.3)$ & & & \\
\hline Active Smoker & & & & 0.219 & & \\
\hline Yes & $82(80.4)$ & $75(82.4)$ & $7(63.6)$ & & & \\
\hline No & $20(19.6)$ & $16(17.6)$ & $4(36.4)$ & & & \\
\hline Anterolateral & $32(31.4)$ & $28(30.8)$ & $4(26.4)$ & & & \\
\hline Lateral & $28(27.5)$ & $25(27.5)$ & $3(27.3)$ & & & \\
\hline Posterolateral & 19 (18.6) & $17(18.7)$ & $2(18.2)$ & & & \\
\hline Posterior & $12(11.8)$ & $12(13.2)$ & 0 & & & \\
\hline Tumor size & & & & 0.389 & & \\
\hline$\leq 5 \mathrm{~cm}$ & $34(33.3)$ & $32(35.2)$ & $2(18.2)$ & & & \\
\hline $5.1-10 \mathrm{~cm}$ & $40(39.2)$ & $36(39.6)$ & $4(26.4)$ & & & \\
\hline $10.1-15 \mathrm{~cm}$ & $15(14.7)$ & $13(14.3)$ & $2(18.2)$ & & & \\
\hline$>15 \mathrm{~cm}$ & $13(12.7)$ & $10(11)$ & $3(27.3)$ & & & \\
\hline Histologic Subtype & & & & 0.233 & & \\
\hline Undifferentiated pleomorphic & $24(23.5)$ & $21(23.1)$ & $3(27.3)$ & & & \\
\hline Liposarcoma & $17(16.7)$ & $16(17.6)$ & $1(9.1)$ & & & \\
\hline Angiosarcoma & $10(9.8)$ & $7(7.7)$ & $3(27.3)$ & & & \\
\hline Dermatofibrosarcoma & $8(7.8)$ & $8(8.8)$ & 0 & & & \\
\hline Fibrosarcoma & $7(6.9)$ & $5(5.5)$ & $2(18.2)$ & & & \\
\hline Leiomyosarcoma & $7(6.9)$ & $7(7.7)$ & 0 & & & \\
\hline
\end{tabular}


Table 2. Cont.

\begin{tabular}{|c|c|c|c|c|c|c|}
\hline Variable & $\begin{array}{l}\text { All Patients } \\
(\mathrm{n}=102)\end{array}$ & $\begin{array}{l}\text { No Wound Complications } \\
(\mathrm{n}=91)\end{array}$ & $\begin{array}{l}\text { Wound Complications } \\
(\mathrm{n}=11)\end{array}$ & $\begin{array}{c}\text { Comparison, } \\
p \text {-value }\end{array}$ & $\begin{array}{l}\text { Logistic Multivariate } \\
\text { Regression, } p \text {-value }\end{array}$ & $\begin{array}{l}\text { Odds Ratio } \\
(95 \% \mathrm{CI})\end{array}$ \\
\hline UICC-Stage & & & & 0.138 & & \\
\hline I & $33(32.4)$ & $31(34.1)$ & $2(18.2)$ & & & \\
\hline II & $13(12.7)$ & $13(14.3)$ & 0 & & & \\
\hline III & $56(54.9)$ & $47(51.6)$ & $9(81.8)$ & & & \\
\hline Tumor Grade & & & & 0.425 & & \\
\hline G1 & $34(33.3)$ & $32(35.2)$ & $2(18.2)$ & & & \\
\hline $\mathrm{G} 2$ & $29(28.4)$ & $26(28.6)$ & $3(27.3)$ & & & \\
\hline G3 & $39(38.2)$ & $33(36.2)$ & $6(54.5)$ & & & \\
\hline Prior external biopsy/incomplete resection & & & & 0.980 & & \\
\hline Yes & $46(45.1)$ & $41(45.1)$ & $5(45.5)$ & & & \\
\hline No & $56(54.9)$ & $50(54.9)$ & $6(54.5)$ & & & \\
\hline Resection status & & & & 0.515 & & \\
\hline R0 & $94(92.2)$ & $84(92.3)$ & $10(90.1)$ & & & \\
\hline R1 & $4(3.9)$ & $4(4.4)$ & 0 & & & \\
\hline R2 & $4(3.9)$ & $3(3.3)$ & $1(9.9)$ & & & \\
\hline Operative time in minutes, mean & $111.1 \pm 72.5$ & $105,5 \pm 69.2$ & $158.1 \pm 86$ & 0.029 & 0.025 & $1.01(1.001-1.02)$ \\
\hline Full thickness resection & & & & 0.239 & & \\
\hline Yes & $39(38.2)$ & $33(36.3)$ & $6(54.5)$ & & & \\
\hline No & $63(61.8)$ & $58(63.7)$ & $5(45.5)$ & & & \\
\hline Soft tissue reconstruction & & & & 0.279 & & \\
\hline Primary Closure & $70(68.6)$ & $64(70.3)$ & $6(54.5)$ & & & \\
\hline Skin graft & $7(6.9)$ & $7(7.7)$ & 0 & & & \\
\hline Local flap & $24(23.5)$ & $19(20.9)$ & $5(45.5)$ & & & \\
\hline Free flap & $1(1)$ & $1(1.1)$ & 0 & & & \\
\hline Neoadjuvant Treatment & & & & 1.000 & & \\
\hline Yes & $5(4.9)$ & $5(5.5)$ & 0 & & & \\
\hline No & $97(95.1)$ & $86(94.5)$ & $11(100)$ & & & \\
\hline Adjuvant radiotherapy & & & & 0.744 & & \\
\hline Yes & $35(34.3)$ & $32(35.2)$ & $3(27.3)$ & & & \\
\hline No & $67(65.7)$ & $59(64.8)$ & $8(72.7)$ & & & \\
\hline Length of stay in days, mean & $13.4 \pm 10.4$ & $11.4 \pm 5.8$ & $29.5 \pm 21.6$ & $<0.001$ & & \\
\hline
\end{tabular}

Data reported as $\mathrm{n}(\%)$ or mean \pm standard deviation; BMI body mass index, ASA American Society of Anesthesiologists, UICC Union internationale contre le cancer, ${ }^{*}$ variable was eliminated in stepwise regression. 


\subsection{Follow-Up}

The median follow-up of surviving patients was 10.1 years, and $73.5 \%$ of surviving patients had a follow-up after at least 60 months.

A total of 36 patients (34.5\%) developed a recurrence during the follow-up period, the 5-year LRFS was $67.5 \%$, and the 10 -year LRFS was $61.2 \%$. Meanwhile, 22 patients $(21.2 \%)$ developed metastases, the 5-year MFS was $78.3 \%$, and the 10-year MFS was $71.9 \%$. Among patients with recurrence, 20 had a single recurrence, nine had two recurrences and seven had three or more recurrences. A total of 35 patients (33.7\%) died during the follow-up period, resulting in a 5-year Overall survival (OS) of $72.7 \%$ and a 10 year-OS of $61.2 \%$. A total of 26 deaths were disease specific, resulting in a 5-year DSS of $73.5 \%$ and a 10 -year DSS of $70.9 \%$.

A total of eight patients with incomplete resections ( $R 1, n=4$ and $R 2, n=4)$ were excluded from analysis of predictors of outcome. Univariate analysis results of predictors of 5-LRFS, MFS, and DSS are presented in Table 3, along with multivariate analysis in Table 4. 
Table 3. Univariate analysis of factors associated with 5-y LRFS, MFS, and DSS.

\begin{tabular}{|c|c|c|c|c|c|c|c|}
\hline Variable & $\mathbf{n}$ & 5-y-LRFS & $p$-value (Log Rank) & 5-y-MFS & $p$-value (Log Rank) & 5-y-DSS & $p$-value (Log Rank) \\
\hline All patients & 94 & $67.8 \pm 5$ & & $80.3 \pm 4.5$ & & $79.5 \pm 4.5$ & \\
\hline Sex & & & 0.005 & & 0.550 & & 0.189 \\
\hline Male & 45 & $81.4 \pm 5.9$ & & $83.9 \pm 5.6$ & & $84.9 \pm 5.7$ & \\
\hline Female & 49 & $55.1 \pm 7.4$ & & $76.1 \pm 7.2$ & & $74.1 \pm 6.8$ & \\
\hline Age at operation & & & 0.057 & & 0.036 & & 0.023 \\
\hline$\leq 39$ & 19 & $89.5 \pm 7$ & & $94.7 \pm 5.1$ & & - & \\
\hline $40-64$ & 38 & $68 \pm 7.6$ & & $83.8 \pm 6.8$ & & $77.6 \pm 7.7$ & \\
\hline$\geq 65$ & 37 & $55.3 \pm 8.8$ & & $66.4 \pm 9.1$ & & $69.0 \pm 8.3$ & \\
\hline Obesity $\left(\mathrm{BMI}>30 \mathrm{~kg} / \mathrm{m}^{2}\right)$ & & & 0.732 & & 0.874 & & 0.336 \\
\hline Yes & 18 & $72.2 \pm 10.6$ & & $83.3 \pm 8.8$ & & $88.9 \pm 7.4$ & \\
\hline No & 76 & $66.7 \pm 5.6$ & & $79.1 \pm 5.3$ & & $76.8 \pm 5.3$ & \\
\hline ASA-Classification & & & 0.009 & & 0.208 & & 0.238 \\
\hline 1 & 20 & $95 \pm 4.9$ & & $90 \pm 6.7$ & & $89.7 \pm 6.9$ & \\
\hline 2 & 51 & $62.4 \pm 7.1$ & & $80.8 \pm 6.2$ & & $78.3 \pm 6.5$ & \\
\hline 3 & 21 & $52.4 \pm 10.9$ & & $69.3 \pm 11.9$ & & $75.9 \pm 9.4$ & \\
\hline 4 & 2 & - & & $50 \pm 35.4$ & & $50 \pm 35.4$ & \\
\hline Cardiovascular Morbidity & & & 0.005 & & 0.011 & & 0.001 \\
\hline Yes & 36 & $48.9 \pm 9.1$ & & $62.5 \pm 10.3$ & & $59.7 \pm 9.5$ & \\
\hline No & 58 & $78.6 \pm 5.5$ & & $88.7 \pm 4.4$ & & $90.5 \pm 4.1$ & \\
\hline Active Smoker & & & 0.921 & & 0.947 & & 0.641 \\
\hline Yes & 19 & $68.4 \pm 10.7$ & & $81.5 \pm 9.8$ & & $78.6 \pm 9.5$ & \\
\hline No & 75 & $67.7 \pm 5.6$ & & $80 \pm 5.1$ & & $79.9 \pm 5.1$ & \\
\hline Tumor depth & & & 0.150 & & 0.064 & & 0.158 \\
\hline Superficial & 29 & $77.9 \pm 8$ & & $91.3 \pm 5.9$ & & $87.9 \pm 6.6$ & \\
\hline Deep & 65 & $63.4 \pm 6.1$ & & $75.4 \pm 5.9$ & & $75.8 \pm 5.7$ & \\
\hline Tumor location (thorax region) & & & 0.773 & & 0.837 & & 0.174 \\
\hline Anterior & 11 & $72.7 \pm 13.4$ & & $90.9 \pm 8.7$ & & $90.9 \pm 8.7$ & \\
\hline Anterolateral & 27 & $61.4 \pm 9.7$ & & $80.9 \pm 8.8$ & & $75.7 \pm 8.7$ & \\
\hline Lateral & 26 & $67.2 \pm 9.6$ & & $79.9 \pm 8.1$ & & $64.6 \pm 10.4$ & \\
\hline Posterolateral & 19 & $68.4 \pm 10.7$ & & $80.7 \pm 10.3$ & & $90.9 \pm 8.7$ & \\
\hline Posterior & 11 & $80 \pm 12.6$ & & $70 \pm 14.5$ & & $88.9 \pm 10.5$ & \\
\hline Tumor size & & & 0.001 & & 0.003 & & 0.019 \\
\hline$\leq 5 \mathrm{~cm}$ & 33 & $74.5 \pm 7.9$ & & $81.9 \pm 7.5$ & & $83 \pm 7$ & \\
\hline $5.1-10 \mathrm{~cm}$ & 35 & $76.2 \pm 7.4$ & & $84.3 \pm 6.5$ & & $83.1 \pm 7$ & \\
\hline $10.1-15 \mathrm{~cm}$ & 15 & $66.7 \pm 12.2$ & & $92.9 \pm 6.9$ & & $86.2 \pm 9.1$ & \\
\hline$>15 \mathrm{~cm}$ & 11 & $20.5 \pm 12.9$ & & $46.7 \pm 16.6$ & & $48.0 \pm 16.4$ & \\
\hline
\end{tabular}


Table 3. Cont.

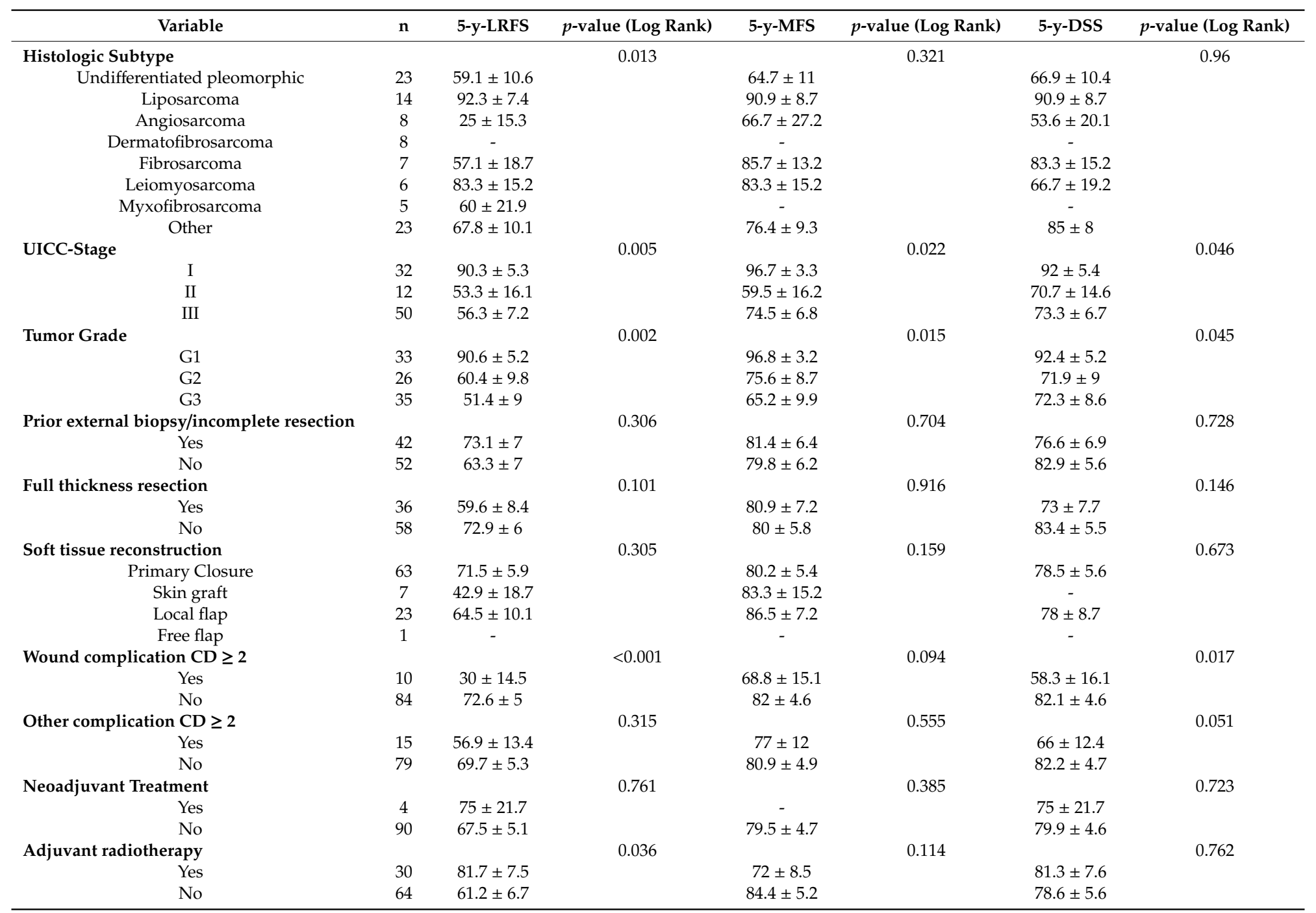

$B M I$ body mass index, ASA American Society of Anesthesiologists, UICC Union internationale contre le cancer. 5-y-LRFS 5-year local recurrence free survival, 5-y-MFS 5-year metastasis free survival, 5-y-DSS 5-year disease free survival. 
Table 4. Multivariate analysis of factors associated with 5-y LRFS, MFS, and DSS.

\begin{tabular}{|c|c|c|c|c|c|c|}
\hline Variable & Hazard Ratio 5-y-LRFS & $p$-value (MVA) & Hazard Ratio 5-y-MFS & $p$-value (MVA) & Hazard Ratio 5-y-DSS & $p$-value (MVA) \\
\hline \multicolumn{7}{|l|}{ Sex } \\
\hline Male & $0.93(0.34-2.58)$ & 0.893 & $2(0.55-7.25)$ & 0.289 & $1.75(0.43-7.13)$ & 0.432 \\
\hline Female & Ref. & & Ref. & & Ref. & \\
\hline \multicolumn{7}{|l|}{ Age at operation } \\
\hline$\leq 39$ & Ref. & & Ref. & & Ref. & \\
\hline $40-64$ & $1.73(0.31-9.73)$ & 0.533 & $1.27(0.85-19.11)$ & 0.861 & - & 0.935 \\
\hline$\geq 65$ & $1.62(0.25-10.52)$ & 0.612 & $3.26(0.17-62.36)$ & 0.433 & - & 0.935 \\
\hline \multicolumn{7}{|l|}{ ASA-Classification } \\
\hline 1 & Ref. & & Ref. & & Ref. & \\
\hline 2 & $4.26(0.44-41.2)$ & 0.21 & $0.73(0.09-5.9)$ & 0.765 & $0.58(0.07-4.6)$ & 0.607 \\
\hline 3 & $4.9(0.47-50.87)$ & 0.183 & $0.62(0.07-5.85)$ & 0.676 & $0.68(0.08-5.38)$ & 0.711 \\
\hline 4 & - & 0.985 & $3.93(0.13-122.81)$ & 0.436 & $2.39(0.1-55)$ & 0.587 \\
\hline \multicolumn{7}{|c|}{ Cardiovascular Morbidity } \\
\hline Yes & $4.07(1.43-11.59)$ & 0.009 & $3.17(0.72-13.91)$ & 0.127 & $11.55(2.23-59.82)$ & 0.004 \\
\hline No & Ref. & & Ref. & & Ref. & \\
\hline \multicolumn{7}{|l|}{ Tumor depth } \\
\hline Superficial & Ref. & & Ref. & & Ref. & \\
\hline Deep & $1.46(0.48-4.42)$ & 0.508 & $1.88(0.3-11.93)$ & 0.503 & $1.5(0.33-6.91)$ & 0.600 \\
\hline \multicolumn{7}{|l|}{ Tumor size } \\
\hline$\leq 5 \mathrm{~cm}$ & Ref. & & Ref. & & Ref. & \\
\hline $5.1-10 \mathrm{~cm}$ & $1.02(0.33-3.16)$ & 0.976 & $0.43(0.09-2.13)$ & 0.301 & $0.65(0.13-3.12)$ & 0.590 \\
\hline $10.1-15 \mathrm{~cm}$ & $0.94(0.27-3.18)$ & 0.916 & $0.08(0.004-1.7)$ & 0.105 & $0.52(0.08-3.37)$ & 0.496 \\
\hline$>15 \mathrm{~cm}$ & $2.06(0.63-6.74)$ & 0.234 & $3.13(0.59-16.64)$ & 0.181 & $1.81(0.35-9.35)$ & 0.480 \\
\hline \multicolumn{7}{|l|}{ Tumor Grade } \\
\hline G1 & Ref. & & Ref. & & Ref. & \\
\hline G2 & $18.76(4.11-85.49)$ & $<0.001$ & $9.05(0.63-129.2)$ & 0.104 & $11.96(1.55-92.4)$ & 0.017 \\
\hline G3 & $10(2.59-38.62)$ & 0.001 & $14.35(1.31-157.35)$ & 0.029 & $6.95(1.04-46.35)$ & 0.045 \\
\hline Histologic Subtype & & 0.307 & & 0.607 & & \\
\hline \multicolumn{7}{|c|}{ Wound complication $C D \geq 2$} \\
\hline Yes & $3.83(1.24-11.85)$ & 0.02 & $3.4(0.66-17.43)$ & 0.142 & $5.31(1.1-25.62)$ & 0.037 \\
\hline No & Ref. & & Ref. & & Ref. & \\
\hline \multicolumn{7}{|c|}{ Other complication $\mathrm{CD} \geq 2$} \\
\hline Yes & $1.15(0.35-3.77)$ & 0.822 & $1.22(0.18-8.35)$ & 0.839 & $2.94(0.6-14.46)$ & 0.184 \\
\hline No & Ref. & & Ref. & & Ref. & \\
\hline \multicolumn{7}{|l|}{ Adjuvant radiotherapy } \\
\hline Yes & $0.09(0.03-0.31)$ & $<0.001$ & $1.1(0.28-4.32)$ & 0.893 & $0.22(0.05-1.02)$ & 0.052 \\
\hline No & Ref. & & Ref. & & Ref. & \\
\hline
\end{tabular}

ASA American Society of Anesthesiologists, 5-y-LRFS 5-year local recurrence free survival, 5-y-MFS 5-year metastasis free survival, 5-y-DSS 5-year disease free survival, Ref. Reference. 


\subsection{Local Recurrence Free Survival (LRFS)}

A total of 29 out of the remaining 94 patients (30.9\%) developed a local recurrence within 5 years. In univariate analysis of 5-year LRFS, female sex, a high ASA-score, and cardiovascular morbidity had a negative impact, but only cardiovascular morbidity was confirmed as a predictive factor in multivariate analysis with a hazard ratio of 4.07 (1.43-11.59) and $p=0.009$. Histopathologic subtype, tumor size, UICC-stage, and tumor grade were predictors of LRFS in univariate analysis. Tumor grade remained an independent predictor in multivariate analysis while the UICC-stage was not included in the model. Wound complications with a CD grade of $\geq 2$ were found to be significantly associated with worse LRFS in univariate and multivariate analysis with a hazard ratio of 3.83 (1.24-11.85), $p=0.02$, and a 5 -year LRFS of $30 \pm 14.5 \%$ versus $72.6 \pm 5 \%$. The Kaplan Meier 5-year LRFS curve for wound complications is shown in Figure 1.

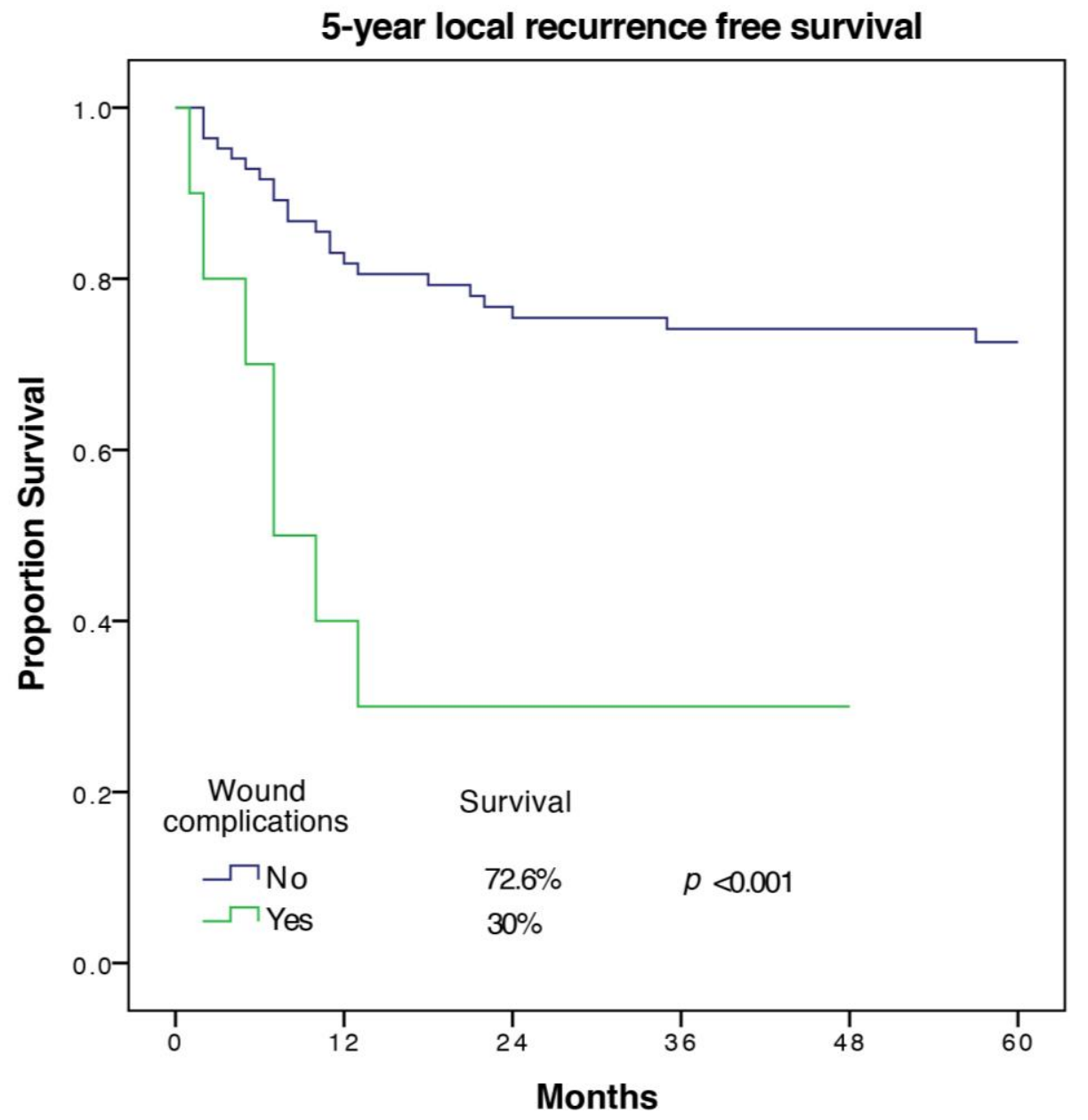

Figure 1. 5-year local recurrence free survival of patients with and without wound complications.

Adjuvant radiation was significantly associated with higher LRFS, both in univariate and multivariate analysis and had a HR of $0.09(0.03-0.31), p<0.001$.

\subsection{Metastasis Free Survival (MFS)}

A total of 16 out of 94 patients (17\%) developed metastases in the first five years. Factors associated with worse MFS on univariate analysis were age $(p=0.035)$, cardiovascular morbidity $(p=0.011)$, tumor size $(p=0.003)$, UICC-stage $(p=0.022)$, and tumor grade $(p=0.015)$. The only significant predictor of MFS on multivariate analysis with exclusion of UICC-stage was tumor grade (HR 14.35 (1.31-157.35), $p=0.029$ for G3 vs. G1). Wound complications were associated with a trend towards 
a lower MFS $(68.8 \pm 15.1 \%$ versus $82 \pm 4.6 \%)$ but did not meet statistical significance in univariate analysis $(p=0.095)$. The Kaplan Meier 5-year MFS curve for wound complications is shown in Figure 2.

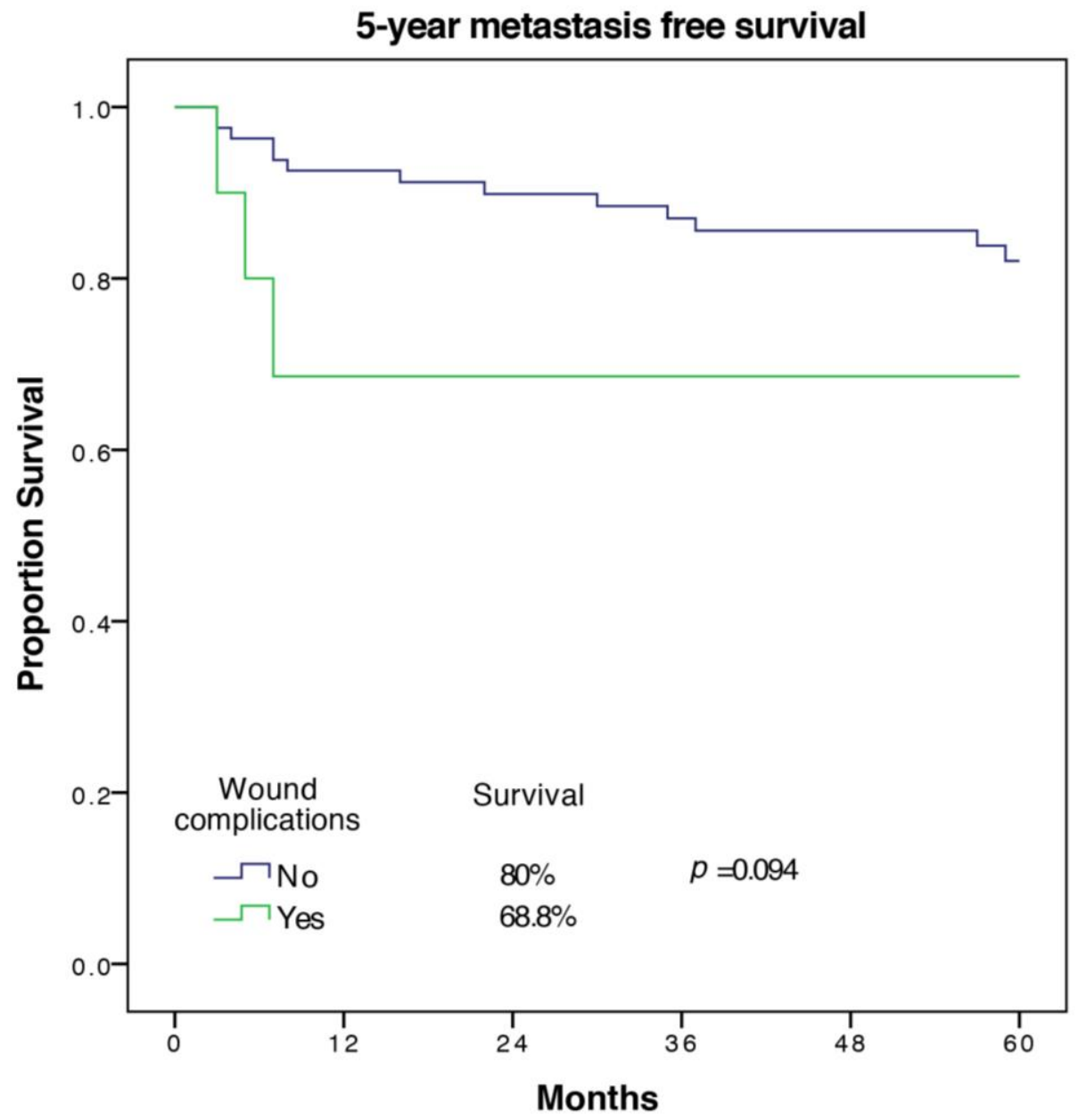

Figure 2. 5-year metastasis free survival of patients with and without wound complications.

\subsection{Disease Specific Survival (DSS)}

A total of 17 out of 94 patients (18\%) died from the underlying disease in the first five years. Factors associated with worse DSS on univariate analysis were age $(p=0.023)$, cardiovascular morbidity $(p=$ $0.001)$, tumor size $(p=0.019)$, UICC-stage $(p=0.046)$, tumor grade $(p=0.045)$, wound complication $(p=0.017)$, and other complication $(p=0.051)$. Significant predictors of DSS in multivariate analysis with the exclusion of the UICC-stage were cardiovascular morbidity (HR $11.55(2.23-59.82), p=0.004)$, as well as tumor grade and wound complications (HR 5.31 (1.1-25.62), $p=0.037$ ). The Kaplan Meier 5-year DSS curve for wound complications is shown in Figure 3. 


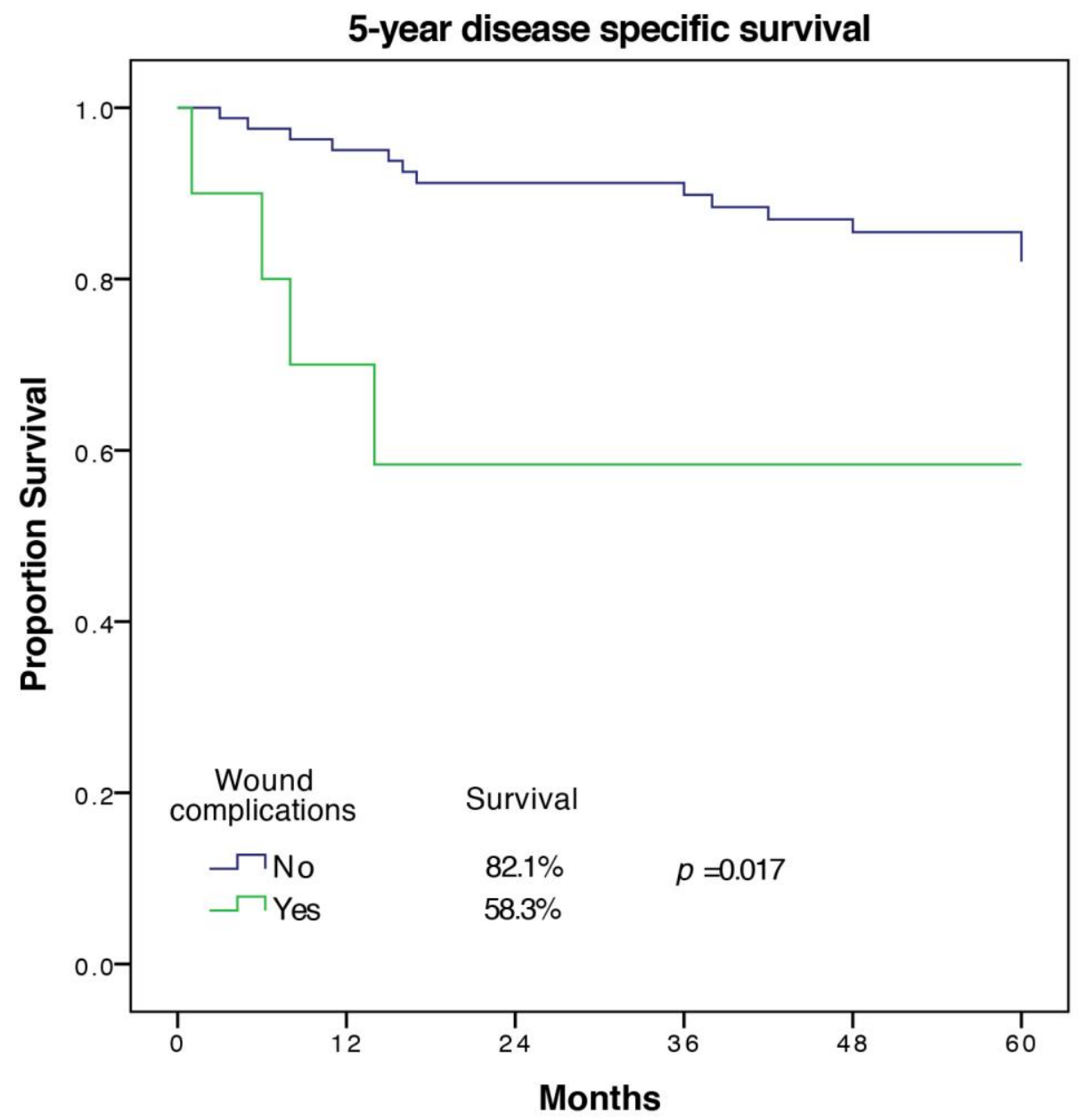

Figure 3. 5-year disease specific survival of patients with and without wound complications.

\section{Discussion}

In the present study, postoperative complications after a resection of 102 primary STS of the chest wall were analyzed and predictors of wound complications were identified. In 94 patients with achieved complete resection (R0), predictors for LRFS, MFS, and DSS were analyzed to examine the impact of wound complications on oncologic outcome.

Most tumors were high grade and larger than $5 \mathrm{~cm}$ in diameter, as in comparable studies in the literature $[5,22-24]$. The 5 -year OS was $72 \%$ and 5-year LRFS was $67.5 \%$ with a median follow-up of 121 months. In a large cohort of 192, examination of the STS of the chest wall from Memorial Sloan Kettering Cancer Center with a median follow up of 51 months provided a 5-year LRFS of $69 \%$ and a 5 -year OS of 73\%, which was comparable to our results [22].

The rate of all complications including CD-grade 1 in our cohort of soft tissue sarcomas of the chest wall with $44 \%$ was comparable to a study of Slump et al. on STS of various locations that required flap coverage and Montgomery et al. on extremity STS [25,26].

Several studies have focused specifically on wound complications after surgical resection of STS and associated risk factors, although these cohorts mostly consist of extremity tumors [7,27-29].

In univariate analysis, obesity was associated with higher wound complications in our cohort. Accordingly, Montgomery et al. found obesity to be associated with both a larger tumor size and higher morbidity as causes of wound complications, and thus that it is eliminated by other factors in multivariate analysis [26].

Our data demonstrated that cardiovascular morbidity is a strong predictor of wound complications, which is in accordance with previous literature [25]. Operative time was also identified as an 
independent predictor of wound complications in our cohort and is a result of multiple factors such as tumor size, depth, complexity, morbidity of general anesthesia time, and possibly hypothermia. Analogously to other studies, patients who received skin grafting or flap coverage did not have higher wound complication rates [28,30].

In our analyses, we identified morbidity and tumor grade as predictors of oncologic outcome, which is in accordance with previous literature on truncal and extremity STS, albeit in other studies, age as a surrogate of morbidity was analyzed rather than morbidity itself [22,31,32].

Wound complications were identified as an independent predictor of local recurrence and disease specific death.

Only two studies have so far addressed the oncologic impact of complications in STS to our knowledge. Behnke et al. did not find a correlation of infectious wound complications with LRFS, MFS or DSS in 396 soft tissue sarcomas of the extremities with unreported median follow-up [19]. In contrast, Broecker et al. did find a significant impact of general complications on DSS in 546 patients with extremities and trunk STS after a median follow-up of 37 months, while influence on local recurrence was not significant [20].

Distribution of neoadjuvant radiation therapy differed significantly between groups and incomplete resections were included in both studies.

In our cohort of patients, less than $5 \%$ received neoadjuvant treatment and the proportion of patients who received adjuvant therapy did not differ substantially between groups with and without wound complications ( $27 \%$ vs. $35 \%$ ). Only patients with microscopically clear surgical margins (R0) were included in the outcome analysis.

In a randomized controlled trial of neoadjuvant versus adjuvant radiotherapy for extremity STS, O'Sullivan et al. found no differences in LRFS despite a higher rate of wound complications in patients receiving neoadjuvant radiation therapy [8] In our series, only three patients received neoadjuvant therapy and thus no conclusions on the role of neoadjuvant therapy could be drawn. It is unclear whether a negative impact of wound complications exists only in STS without prior radiation. Further studies are needed to address this important question.

An association of local inflammatory complications with cancer recurrence has been demonstrated for multiple malignancies as discussed in the introduction of this article. It has been shown that most STS maintain an inflammatory microenvironment with an observed secretion of IL6, a proinflammatory cytokine [33]. Its use as a biomarker and therapeutic target has been the subject of studies [34,35]. In breast cancer, IL6 was able to activate dormant cancer cells, a mechanism that could also be relevant for sarcoma recurrence after local resection [36]. In a murine study, induced secretion of IL1 $\beta$, one of the central mediators of acute infection, led to increased proliferation, migration, and invasion capacity of fibrosarcoma cells [37].

Therefore, although there are hints in the literature, the interaction between inflammation and STS deserves further investigations.

At the same time, inflammation has been shown to play an essential role in cardiovascular disease such as atherosclerosis [38]. As such, elevated inflammation markers such as C-reactive protein have been shown to be predictive of cardiovascular disease and cardiovascular events suggestive of ongoing mild systemic inflammation in these patients $[39,40]$. Interestingly, the Emerging Risk Factors Collaboration also found elevated inflammation markers to be predictive of death for several cancers, suggesting a clinical link between systemic inflammation and malignant disease [40]. This can partly explain our findings of cardiovascular morbidity being a risk factor for worse LRFS and DSS, potentially by increasing wound complications and continuously elevated levels of systematic inflammation.

The most identified risk factors for wound complications after STS resection in this or other studies are intrinsic to the patient (morbidity) or the tumor (size, operation time) and do not allow modification by the surgeon. However, they aid in the identification of patients at elevated risk for wound complications and adaption of surgical or perioperative treatment to this risk. 
Patients who received complex soft tissue reconstruction after sarcoma resection did not have a higher rate of wound complications than patients with primary wound closure in this or previous studies $[28,30]$. For this reason, flap reconstruction should be considered with a low threshold whenever primary closure is regarded to be at risk. Ultimately, strategies to reduce wound complications and possibly improve oncologic outcome need to be developed and implemented.

Certain limitations of this study exist that are inherent to its retrospective nature and the sample size due to rarity of STS of the chest wall. While the causal correlation of wound complications with oncologic outcomes for STS cannot be established by our data, the previous experimental research cited here and similar associations in more prevalent malignancies support these findings.

\section{Materials and Methods}

The study was approved by the ethical committee of the Ruhr-University Bochum, approval number: 18-6469-BR. All of the patients who underwent resection of a STS of the thoracic trunk from January 1995 until December 2016 at our institution were identified. Only primary tumors without dissemination were included in the study.

Retrospectively, demographic, clinical and outcome data were obtained from the medical records. Tumors were classified by the AJCC/UICC 8th edition [41].

New follow-up data on recurrence, metastases, and survival were obtained prospectively by correspondence with patients or relatives. Complications occurring within 90 days of initial operation were identified and classified by the modified Clavien-Dindo classification, which is based on the therapy necessary to treat the complication [21]. A summary of the classification is presented in Table 1. Wound complications were defined as surgical site infections or wound dehiscence. According to the Clavien-Dindo classification, grade one wound complications received no intervention (or bedside wound opening), grade two typically received antibiotic treatment, and grade three wound complications needed operative revision.

Cardiovascular morbidity was defined by a preexisting diagnosis of cardiovascular disease and included coronary or peripheral artery disease.

The primary outcome was 5-year local recurrence free survival (LRFS), while the secondary outcomes were 5-year metastasis free survival (MFS) and 5-year disease specific survival (DSS). For outcome analysis, all patients with incomplete $(R 1, R 2)$ resections or metastatic disease were excluded and only complications with a Clavien-Dindo grade of 2 or higher were considered.

LRFS was calculated from the date of resection until tumor recurrence or until the last follow-up in patients without recurrence. MFS was calculated from the date of resection until the occurrence of metastases or until the last follow-up in patients without metastasis. DSS was calculated from the date of resection until disease specific death or the last follow-up in patients without disease specific death. Here, the cause of death was assessed by correspondence with relatives and assumed in the presence of metastatic disease.

\subsection{Treatment}

Preoperatively, computed tomography scans and/or contrast-enhanced magnetic resonance imaging (MRI) of the chest and the tumor site were routinely performed. The surgical aim for all patients was complete resection of the primary tumor with negative margins. A lateral clear margin of $2 \mathrm{~cm}$ of healthy tissue was ensured whenever possible. In epifascial lesions, a deep clear margin of one fascial layer was intended. Full-thickness chest wall resections were performed on lesions infiltrating the ribs or intercostal space. Indications for adjuvant radiation or chemotherapy were given at the discretion of our interdisciplinary tumor board.

Following surgical treatment, the follow-up management for all patients included clinical examinations, chest $\mathrm{X}$-rays, and contrast-enhanced MRIs every three months for the first two years, and then every six months for the next three years. The decision for whether follow-up MRIs and chest 
X-rays would be continued after five years was based on previous tumor behavior and the decision of the informed patient.

\subsection{Statistics}

SPSS Version 21 for Mac (IBM, Armonk, New York, USA) was used for all analysis. Data are presented as means \pm standard deviation or median. Comparison of patients with and without wound complications was performed via chi-square or fisher exact test for categorical variables and the independent $\mathrm{t}$-test for continuous variables. Subsequent multivariate regression analysis of factors with $p<0.01$ with backwards elimination was performed to identify independent predictors. Hazard ratio was calculated and is presented as $\mathrm{HR}(95 \% \mathrm{CI})$.

For the patients included in the outcome analysis, survival analyses were conducted using Kaplan-Meier log-rank tests and multivariate Cox regression with the enter method, including all factors with $p<0.01$ in log rank testing for at least one outcome measure except for the UICC-stage. $p<0.05$ was considered as statistically significant.

\section{Conclusions}

We were able to identify wound complications as an independent predictor of local recurrence and disease specific death in our single institution cohort of primary STS of the chest wall. Patients at risk of wound complications after STS resection should be identified and strategies implemented to reduce surgical complications and possibly improve oncologic prognosis.

Author Contributions: Conceptualization, M.D.; formal analysis, M.D., P.K., J.M.W., K.H.; investigation, P.K.; writing—original draft preparation, M.D.; writing—review and editing, P.K., J.M.W., C.W., M.S., M.L., B.B., K.H.; visualization, C.W.; supervision, M.L., B.B., K.H.; project administration, B.B. All authors have read and agreed to the published version of the manuscript.

Funding: This research received no external funding.

Acknowledgments: We acknowledge support by the DFG Open Access Publication Funds of the Ruhr-University Bochum.

Conflicts of Interest: The authors declare no conflict of interest.

\section{References}

1. Jemal, A.; Siegel, R.; Xu, J.; Ward, E. Cancer statistics, 2010. CA A Cancer J. Clin. 2010, 60, 277-300. [CrossRef] [PubMed]

2. Gross, J.L.; Younes, R.N.; Haddad, F.J; Deheinzelin, D.; Pinto, C.A.; Costa, M.L. Soft-tissue sarcomas of the chest wall: prognostic factors. Chest 2005, 127, 902-908. [CrossRef] [PubMed]

3. Gordon, M.S.; Hajdu, S.I.; Bains, M.S.; Burt, M.E. Soft tissue sarcomas of the chest wall. Results of surgical resection. J. Thorac. Cardiovasc. Surg. 1991, 101, 843-854. [CrossRef]

4. Harati, K.; Kolbenschlag, J.; Bohm, J.; Niggemann, H.; Joneidi-Jafari, H.; Stricker, I.; Lehnhardt, M.; Daigeler, A. Long-term outcomes of patients with soft tissue sarcoma of the chest wall: Analysis of the prognostic significance of microscopic margins. Oncol. Lett. 2018, 15, 2179-2187. [CrossRef] [PubMed]

5. Salas, S.; Bui, B.; Stoeckle, E.; Terrier, P.; Ranchere-Vince, D.; Collin, F.; Leroux, A.; Guillou, L.; Michels, J.J.; Trassard, M.; et al. Soft tissue sarcomas of the trunk wall (STS-TW): a study of 343 patients from the French Sarcoma Group (FSG) database. Ann. Oncol. 2009, 20, 1127-1135. [CrossRef] [PubMed]

6. Soerensen, T.R.; Raedkjaer, M.; Jorgensen, P.H.; Hoejsgaard, A.; Safwat, A.; Baad-Hansen, T. Soft Tissue Sarcomas of the Thoracic Wall: More Prone to Higher Mortality, and Local Recurrence-A Single Institution Long-Term Follow-up Study. Int. J. Surg. Oncol. 2019, 2019, 2350157. [CrossRef]

7. Baldini, E.H.; Lapidus, M.R.; Wang, Q.; Manola, J.; Orgill, D.P.; Pomahac, B.; Marcus, K.J.; Bertagnolli, M.M.; Devlin, P.M.; George, S.; et al. Predictors for major wound complications following preoperative radiotherapy and surgery for soft-tissue sarcoma of the extremities and trunk: importance of tumor proximity to skin surface. Ann. Surg. Oncol. 2013, 20, 1494-1499. [CrossRef] 
8. Davis, A.M.; O'Sullivan, B.; Turcotte, R.; Bell, R.; Catton, C.; Chabot, P.; Wunder, J.; Hammond, A.; Benk, V.; Kandel, R.; et al. Late radiation morbidity following randomization to preoperative versus postoperative radiotherapy in extremity soft tissue sarcoma. Radiother. Oncol. 2005, 75, 48-53. [CrossRef]

9. O'Sullivan, B.; Davis, A.M.; Turcotte, R.; Bell, R.; Catton, C.; Chabot, P.; Wunder, J.; Kandel, R.; Goddard, K.; Sadura, A.; et al. Preoperative versus postoperative radiotherapy in soft-tissue sarcoma of the limbs: A randomised trial. Lancet 2002, 359, 2235-2241. [CrossRef]

10. Schreiber, D.; Rineer, J.; Katsoulakis, E.; Sroufe, R.L.; Lange, C.S.; Nwokedi, E.; Schwartz, D.; Choi, K.; Rotman, M. Impact of postoperative radiation on survival for high-grade soft tissue sarcoma of the extremities after limb sparing radical resection. Am. J. Clin. Oncol. 2012, 35, 13-17. [CrossRef]

11. Schütte, J.; Bauer, S.; Brodowicz, T.; Grünwald, V.; Hofer, S.; Hohenberger, P.; Jost, L.; Kasper, B.; Lindner, L.H.; Pritzkuleit, R.; et al. Onkopedia Leitlinie Weichgewebssarkome (maligne Weichgewebstumoren) des Erwachsenen. Ger. Soc. Haematol. Oncol. 2019.

12. Andreou, A.; Biebl, M.; Dadras, M.; Struecker, B.; Sauer, I.M.; Thuss-Patience, P.C.; Chopra, S.; Fikatas, P.; Bahra, M.; Seehofer, D.; et al. Anastomotic leak predicts diminished long-term survival after resection for gastric and esophageal cancer. Surgery 2016, 160, 191-203. [CrossRef] [PubMed]

13. Hayashi, T.; Yoshikawa, T.; Aoyama, T.; Hasegawa, S.; Yamada, T.; Tsuchida, K.; Fujikawa, H.; Sato, T.; Ogata, T.; Cho, H.; et al. Impact of infectious complications on gastric cancer recurrence. Gastric Cancer 2015, 18, 368-374. [CrossRef] [PubMed]

14. McArdle, C.S.; McMillan, D.C.; Hole, D.J. Impact of anastomotic leakage on long-term survival of patients undergoing curative resection for colorectal cancer. Br. J. Surg. 2005, 92, 1150-1154. [CrossRef] [PubMed]

15. Jackson, R.M.; Rice, D.H. Wound infections and recurrence in head and neck cancer. Otolaryngol. Head Neck Surg. 1990, 102, 331-333. [CrossRef] [PubMed]

16. Rodrigo, J.P.; Suarez, C. Prognostic significance of postoperative wound infection on head and neck cancer. Otolaryngol. Head Neck Surg. 1998, 118, 272-275. [CrossRef]

17. Beecher, S.M.; O'Leary, D.P.; McLaughlin, R.; Sweeney, K.J.; Kerin, M.J. Influence of complications following immediate breast reconstruction on breast cancer recurrence rates. Br. J. Surg. 2016, 103, 391-398. [CrossRef]

18. Murthy, B.L.; Thomson, C.S.; Dodwell, D.; Shenoy, H.; Mikeljevic, J.S.; Forman, D.; Horgan, K. Postoperative wound complications and systemic recurrence in breast cancer. Br. J. Cancer 2007, 97, 1211-1217. [CrossRef]

19. Behnke, N.K.; Alamanda, V.K.; Song, Y.; Archer, K.R.; Halpern, J.L.; Schwartz, H.S.; Holt, G.E. Does postoperative infection after soft tissue sarcoma resection affect oncologic outcomes? J. Surg. Oncol. 2014, 109, 415-420. [CrossRef]

20. Broecker, J.S.; Ethun, C.G.; Monson, D.K.; Lopez-Aguiar, A.G.; Le, N.; McInnis, M.; Godette, K.; Reimer, N.B.; Oskouei, S.V.; Delman, K.A.; et al. The Oncologic Impact of Postoperative Complications Following Resection of Truncal and Extremity Soft Tissue Sarcomas. Ann. Surg. Oncol. 2017, 24, 3574-3586. [CrossRef]

21. Dindo, D.; Demartines, N.; Clavien, P.A. Classification of surgical complications: a new proposal with evaluation in a cohort of 6336 patients and results of a survey. Ann. Surg. 2004, 240, 205-213. [CrossRef] [PubMed]

22. McMillan, R.R.; Sima, C.S.; Moraco, N.H.; Rusch, V.W.; Huang, J. Recurrence patterns after resection of soft tissue sarcomas of the chest wall. Ann. Thorac. Surg. 2013, 96, 1223-1228. [CrossRef] [PubMed]

23. Kuwahara, H.; Salo, J.; Nevala, R.; Tukiainen, E. Single-Institution, Multidisciplinary Experience of Soft Tissue Sarcomas in the Chest Wall. Ann. Plast. Surg. 2019. [CrossRef] [PubMed]

24. Tsukushi, S.; Nishida, Y.; Sugiura, H.; Nakashima, H.; Ishiguro, N. Soft tissue sarcomas of the chest wall. J. Thorac. Oncol. 2009, 4, 834-837. [CrossRef] [PubMed]

25. Slump, J.; Ferguson, P.C.; Wunder, J.S.; Griffin, A.M.; Hoekstra, H.J.; Liu, X.; Hofer, S.O.P.; O’Neill, A.C. Patient, tumour and treatment factors affect complication rates in soft tissue sarcoma flap reconstruction in a synergistic manner. Eur. J. Surg. Oncol. 2017, 43, 1126-1133. [CrossRef] [PubMed]

26. Montgomery, C.; Harris, J.; Siegel, E.; Suva, L.; Wilson, M.; Morell, S.; Nicholas, R. Obesity is associated with larger soft-tissue sarcomas, more surgical complications, and more complex wound closures (obesity leads to larger soft-tissue sarcomas). J. Surg. Oncol. 2018, 118, 184-191. [CrossRef] [PubMed]

27. Miller, E.D.; Mo, X.; Andonian, N.T.; Haglund, K.E.; Martin, D.D.; Liebner, D.A.; Chen, J.L.; Iwenofu, O.H.; Chakravarti, A.; Scharschmidt, T.J.; et al. Patterns of major wound complications following multidisciplinary therapy for lower extremity soft tissue sarcoma. J. Surg. Oncol. 2016, 114, 385-391. [CrossRef] 
28. Moore, J.; Isler, M.; Barry, J.; Mottard, S. Major wound complication risk factors following soft tissue sarcoma resection. Eur. J. Surg. Oncol. 2014, 40, 1671-1676. [CrossRef]

29. Stevenson, M.G.; Ubbels, J.F.; Slump, J.; Huijing, M.A.; Bastiaannet, E.; Pras, E.; Hoekstra, H.J.; Been, L.B. Identification of predictors for wound complications following preoperative or postoperative radiotherapy in extremity soft tissue sarcoma. Eur. J. Surg. Oncol. 2018, 44, 816-822. [CrossRef]

30. Slump, J.; Hofer, S.O.P.; Ferguson, P.C.; Wunder, J.S.; Griffin, A.M.; Hoekstra, H.J.; Bastiaannet, E.; O’Neill, A.C. Flap reconstruction does not increase complication rates following surgical resection of extremity soft tissue sarcoma. Eur. J. Surg. Oncol. 2018, 44, 251-259. [CrossRef]

31. Stojadinovic, A.; Leung, D.H.; Hoos, A.; Jaques, D.P.; Lewis, J.J.; Brennan, M.F. Analysis of the prognostic significance of microscopic margins in 2084 localized primary adult soft tissue sarcomas. Ann. Surg. 2002, 235, 424-434. [CrossRef] [PubMed]

32. Smith, H.G.; Memos, N.; Thomas, J.M.; Smith, M.J.; Strauss, D.C.; Hayes, A.J. Patterns of disease relapse in primary extremity soft-tissue sarcoma. Br. J. Surg. 2016, 103, 1487-1496. [CrossRef] [PubMed]

33. Radons, J. The role of inflammation in sarcoma. Adv. Exp. Med. Biol. 2014, 816, 259-313. [CrossRef] [PubMed]

34. Hagi, T.; Nakamura, T.; Iino, T.; Matsubara, T.; Asanuma, K.; Matsumine, A.; Sudo, A. The diagnostic and prognostic value of interleukin-6 in patients with soft tissue sarcomas. Sci. Rep. 2017, 7, 9640. [CrossRef] [PubMed]

35. Jayatilaka, H.; Tyle, P.; Chen, J.J.; Kwak, M.; Ju, J.; Kim, H.J.; Lee, J.S.H.; Wu, P.H.; Gilkes, D.M.; Fan, R.; et al. Synergistic IL-6 and IL-8 paracrine signalling pathway infers a strategy to inhibit tumour cell migration. Nat. Commun. 2017, 8, 15584. [CrossRef] [PubMed]

36. Tivari, S.; Lu, H.; Dasgupta, T.; De Lorenzo, M.S.; Wieder, R. Reawakening of dormant estrogen-dependent human breast cancer cells by bone marrow stroma secretory senescence. Cell Commun. Signal. 2018, 16, 48. [CrossRef]

37. Voronov, E.; Reich, E.; Dotan, S.; Dransh, P.; Cohen, I.; Huszar, M.; Fogel, M.; Kleinman, H.K.; White, R.M.; Apte, R.N. Effects of IL-1 molecules on growth patterns of 3-MCA-induced cell lines: an interplay between immunogenicity and invasive potential. J. Immunotoxicol. 2010, 7, 27-38. [CrossRef]

38. Libby, P. Inflammation in atherosclerosis. Arterioscler. Thromb. Vasc. Biol. 2012, 32, 2045-2051. [CrossRef]

39. Danesh, J.; Wheeler, J.G.; Hirschfield, G.M.; Eda, S.; Eiriksdottir, G.; Rumley, A.; Lowe, G.D.; Pepys, M.B.; Gudnason, V. C-reactive protein and other circulating markers of inflammation in the prediction of coronary heart disease. N. Engl. J. Med. 2004, 350, 1387-1397. [CrossRef]

40. Emerging Risk Factors, C.; Kaptoge, S.; Di Angelantonio, E.; Lowe, G.; Pepys, M.B.; Thompson, S.G.; Collins, R.; Danesh, J. C-reactive protein concentration and risk of coronary heart disease, stroke, and mortality: an individual participant meta-analysis. Lancet 2010, 375, 132-140. [CrossRef]

41. Amin, M.B.; Greene, F.L.; Edge, S.B.; Compton, C.C.; Gershenwald, J.E.; Brookland, R.K.; Meyer, L.; Gress, D.M.; Byrd, D.R.; Winchester, D.P. The Eighth Edition AJCC Cancer Staging Manual: Continuing to build a bridge from a population-based to a more "personalized" approach to cancer staging. CA A Cancer J. Clin. 2017, 67, 93-99. [CrossRef] [PubMed]

(C) 2019 by the authors. Licensee MDPI, Basel, Switzerland. This article is an open access article distributed under the terms and conditions of the Creative Commons Attribution (CC BY) license (http://creativecommons.org/licenses/by/4.0/). 